\title{
A rare case of mucoepidermoid carcinoma of the lingual tonsil with cervical lymph node metastases
}

\author{
Claire M. Lawlor ${ }^{1 *}$, Ryan E. Nelson ${ }^{1}$, Meggie E. Doucet ${ }^{2}$ and Paul L. Friedlander ${ }^{1}$
}

*Correspondence: clawlor@tulane.edu

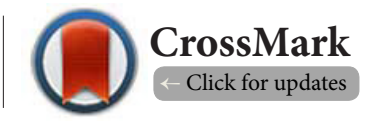

'Department of Otolaryngology, Head and Neck Surgery, Tulane University, Tulane Ave. New Orleans, Louisiana, USA.

${ }^{2}$ Department of Pathology and Laboratory Medicine, Tulane University, Tulane Ave. New Orleans, Louisiana, USA.

\begin{abstract} tonsil. thigh flap followed by adjuvant radiation. presenting a diagnostic and therapeutic dilemma. carcinoma

Oropharyngeal masses suspicious for malignancy are squamous cell carcinoma (SCC) until proven otherwise, as SCC accounts for $>90 \%$ or all oropharyngeal neoplasms [1]. A thorough workup including head and neck imaging, direct laryngoscopy, and tissue biopsy of suspicious lesions is necessary to ensure an accurate diagnosis and proper staging. Here we present a rare case of mucoepidermoid carcinoma arising from the lingual tonsil with metastasis to cervical lymph nodes.
\end{abstract}

Background: Although squamous cell carcinoma accounts for $>90 \%$ of all oropharyngeal neoplasms, other rare neoplasms have been reported. Here, we present a case of mucoepidermoid carcinoma of the lingual

Methods and results: A 66-year-old male presented with a right neck mass and right base of tongue fullness. Fine needle aspiration of the neck mass and surgical biopsy of the base of tongue lesion revealed a low-grade mucoepidermoid carcinoma, ultimately staged as a T4N2aMo neoplasm. Our multi-disciplinary tumor board recommended a right mandibulotomy, partial glossectomy, radical tonsillectomy, lateral pharyngeal wall resection, selective neck dissection levels II-IV, and reconstruction with an anterior lateral

Conclusion: Mucoepidermoid Carcinoma is the most common malignant salivary gland neoplasm; however, mucoepidermoid carcinoma arising from minor salivary rests within the lingual tonsils is exceedingly rare,

Keywords: Mucoepidermoid carcinoma, tongue base, lingual tonsil, oropharyngeal cancer, metastatic

\section{Introduction}

\section{Case presentation}

IRB exemption was obtained from Tulane University prior to reporting this case. A 66-year-old man was referred to our clinic for evaluation of a right neck mass and base of tongue fullness. The mass had been present for five months and did not improve with antibiotics. The patient denied cigarette smoking but endorsed social alcohol use. He also denied hoarseness, dysphagia, odynophagia, otalgia, and unintended weight loss.

On physical examination, he had a $4.0 \mathrm{~cm}$ non-tender, solid, mobile right neck mass at levels II and III. Flexible fiberoptic laryngoscopy (FFL) revealed asymmetry and fullness of the right base of tongue. The remainder of the FFL was unremarkable. A fine needle aspirate (FNA) of the right neck mass was performed, and cytopathology was consistent with a low-grade mucoepidermoid carcinoma (Figure 1A).

Computed tomography (CT) of the neck with angiography revealed asymmetry of the right tonsillolingual sulcus concerning for a neoplastic process. Additionally, two masses measuring $3.6 \times 3.3 \times 3.0 \mathrm{~cm}$ and $3.0 \times 2.4 \times 2.5 \mathrm{~cm}$ with solid and cystic components were noted in the right neck at levels IIA and IIB. Mass effect from these lesions had caused complete collapse of the right jugular vein with apparent thrombosis (Figure 2A). The right carotid artery and left jugular and carotid vessels were grossly patent. No lesions suspicious for neoplasm were identified on CT of the chest and thorax.

The patient was consented for panendoscopy with biopsy for further evaluation and tissue analysis of the right base of tongue lesion. A firm, exophytic mass of the right base of tongue (Figure 2B) with extension into the right lateral pharyngeal wall and inferior pole of the right tonsil was noted on manual exam under anesthesia. 


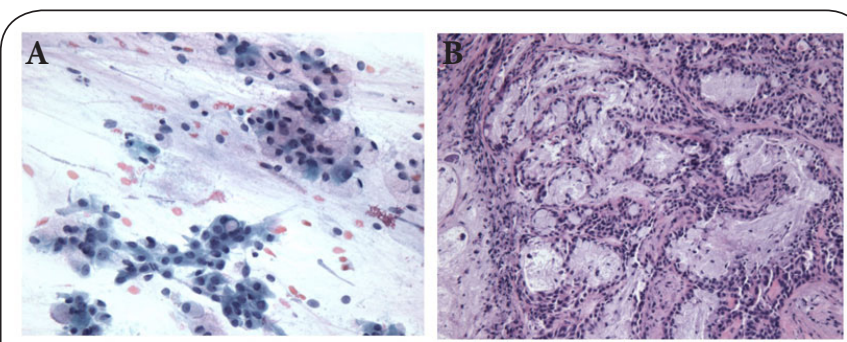

Figure 1. Fine needle aspirate of neck mass and biopsy of base of tongue lesion.

(A) Fine needle aspiration of right neck mass consistent with low-grade mucoepidermoid carcinoma (PAP, magnification X200).

(B) Right base of tongue biopsy demonstrating lowgrade mucoepidermoid carcinoma (hematoxylin-eosin, magnification X200).

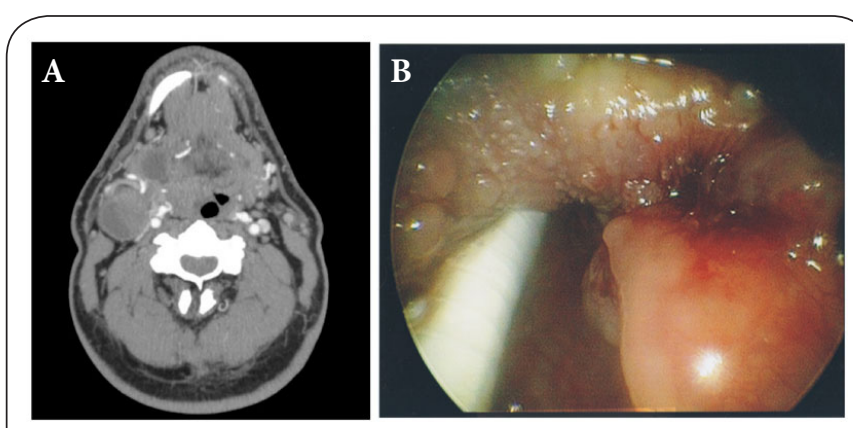

Figure 2. Computed tomography scan and gross specimen of right base of tongue mucoepidermoid carcinoma. (A) Asymmetry of the right tonsillolingual sulcus concerning for Neoplasia can be appreciated. Two masses measuring $3.6 \times 3.3 \times 3.0 \mathrm{~cm}$ and $3.0 \times 2.4 \times 2.5 \mathrm{~cm}$ are seen in the right neck at levels IIA and IIB. Mass effect from these lesions caused compression of the right jugular vein.

(B) A pale, exophytic mass of the right base of tongue was appreciated with direct laryngoscopy.

These findings were confirmed with direct laryngoscopy. Lastly, a Crowe-Davis mouth gag was placed and a $\mathrm{CO} 2$ laser was used to obtain a tissue specimen from the medial portion of the mass at the right lingual tonsil. Frozen section revealed a low-grade mucoepidermoid carcinoma, and final pathology was consistent with this diagnosis (Figure 1B).

Based on the above findings, the patient was diagnosed with a T4N2aMO low-grade mucoepidermoid carcinoma of the right lingual tonsil. The case was discussed at multidisciplinary tumor board, and the team recommended that the patient undergo a right mandibulotomy, partial glossectomy, radical tonsillectomy, lateral pharyngeal wall resection, selective neck dissection levels II-IV, and reconstruction with an anterior lateral thigh flap followed by adjuvant radiation therapy. After several discussions with the patient, he decided to seek an additional opinion at an outside facility prior to surgical management of his disease.

\section{Discussion}

Mucoepidermoid carcinoma (MEC) is the most common malignant salivary gland neoplasm. It arises from the reserve cells of salivary excretory ducts in the major or minor salivary glands. It most commonly presents as a painless, slow-growing, submucosal mass; this insidious presentation can lead to delayed diagnosis and management [2]. The majority of MEC cases occur in the major salivary glands, though it can also arise from minor salivary gland rests in the hard palate, buccal mucosa, lip, and retromolar trigone [3]. MEC has also been known to present as an isolated neck mass.

Rarely, the primary cannot be identified on imaging or biopsy [4]. This diversity of presentation, coupled with the predominance of SCC in the oropharynx, make MEC of the tongue base a diagnostic dilemma.

The literature documenting MEC arising from the lingual tonsils is sparse and consists largely of case reports and case series, many of which include records dating back decades [2,5-13]. The mainstay of treatment for MEC is surgical resection. Need for adjuvant radiation therapy is based on a number of factors, including tumor size, histology, grade, margins, and nodal status [2]. Historically, therapeutic paradigms have based on salivary gland neoplasm pathology regardless of subsite; the paucity of cases inhibits prospective and blinded assessment of therapeutic options for subsites within the oropharynx [14,15]. In 2010, Gopalakrishna lyer et al., performed a retrospective analysis of a series of minor salivary gland tumors of the oropharynx, 26 of which were MEC, and compared treatment modalities using outcomes of overall survival, disease-specific survival, and disease-free survival. Based on their results, they recommend surgical resection of the primary and appropriate management of neck disease for MEC. In their study, adjuvant radiation therapy did not demonstrate statistical benefit though it may still improve outcomes in patients with poor prognostic factors [2].

Despite a FNA of the neck mass demonstrating MEC, our team expected the base of tongue lesion to be a second primary SCC. Based on the final pathology following our panendoscopy, the recommendations of our tumor board were consistent with current standards of care. We present this case to highlight diagnostic dilemma of MEC arising within the lingualton sillar tissue, as well as to emphasize the need for further study into the management of these neoplasms.

\section{Competing interests}

The authors declare that they have no competing interests.

\section{Authors' contributions}

\begin{tabular}{|l|c|c|c|c|}
\hline Authors' contributions & CML & REN & MED & PLF \\
\hline Research concept and design & $\checkmark$ & $\checkmark$ & -- & $\checkmark$ \\
\hline Collection and/or assembly of data & $\checkmark$ & $\checkmark$ & $\checkmark$ & $\checkmark$ \\
\hline Data analysis and interpretation & $\checkmark$ & $\checkmark$ & $\checkmark$ & $\checkmark$ \\
\hline Writing the article & $\checkmark$ & $\checkmark$ & -- & -- \\
\hline Critical revision of the article & $\checkmark$ & -- & -- & -- \\
\hline Final approval of article & $\checkmark$ & -- & -- & $\checkmark$ \\
\hline
\end{tabular}


Publication history

Senior Editor: Jiaoti Huang, David Geffen School of Medicine at UCLA, USA.

Received: 15-Sep-2015 Final Revised: 26-Oct-2015

Accepted: 03-Nov-2015 Published: 09-Nov-2015

\section{References}

1. de Camargo Cancela M, de Souza DL and Curado MP. International incidence of oropharyngeal cancer: a population-based study. Oral Oncol. 2012; 48:484-90. I Article I PubMed

2. Iyer NG, Kim L, Nixon IJ, Palmer F, Kraus D, Shaha AR, Shah JP, Patel SG and Ganly I. Factors predicting outcome in malignant minor salivary gland tumors of the oropharynx. Arch Otolaryngol Head Neck Surg. 2010; 136:1240-7. I Article I PubMed

3. Waldron CA, el-Mofty SK and Gnepp DR. Tumors of the intraoral minor salivary glands: a demographic and histologic study of $\mathbf{4 2 6}$ cases. Oral Surg Oral Med Oral Pathol. 1988; 66:323-33. | Article | PubMed

4. Jarvis SJ, Giangrande V and Brennan PA. Mucoepidermoid carcinoma of the tonsil: a very rare presentation. Acta Otorhinolaryngol Ital. 2013; 33:286-8. | PubMed Abstract | PubMed Full Text

5. Eveson JW and Cawson RA. Tumours of the minor (oropharyngeal) salivary glands: a demographic study of $\mathbf{3 3 6}$ cases. J Oral Pathol. 1985; 14:500-9. | Article | PubMed

6. de Vries EJ, Johnson JT, Myers EN, Barnes EL, Jr. and Mandell-Brown M. Base of tongue salivary gland tumors. Head Neck Surg. 1987; 9:329-31. | Article | PubMed

7. Roper PR, Wolf PF, Luna MA and Goepfert $H$. Malignant salivary gland tumors of the base of the tongue. South Med J. 1987; 80:605-8. | Article I PubMed

8. Kessler DJ, Mickel RA and Calcaterra TC. Malignant salivary gland tumors of the base of the tongue. Arch Otolaryngol. 1985; 111:664-6. | Article I PubMed

9. Goepfert H, Giraldo AA, Byers RM and Luna MA. Salivary gland tumors of the base of the tongue. Arch Otolaryngol. 1976; 102:391-5. I Article I PubMed

10. Chijiwa H, Sakamoto K, Umeno H, Nakashima T, Suzuki G and Hayafuchi N. Minor salivary gland carcinomas of oral cavity and oropharynx. J Laryngol Otol Suppl. 2009; 52-7. I Article I PubMed

11. Hosokawa Y, Shirato H, Kagei K, Hashimoto S, Nishioka T, Tei K, Ono M, Ohmori K, Kaneko M, Miyasaka K and Nakamura M. Role of radiotherapy for mucoepidermoid carcinoma of salivary gland. Oral Oncol. 1999; 35:105-11. | Article | PubMed

12. Gregor RT and Heng BB. Minor salivary gland carcinomas of the mouth and oropharynx. J Otolaryngol. 1981; 10:267-72. I Article I PubMed

13. Martellucci S, Pagliuca G, de Vincentiis M, Rosato C, Scaini E, Gallipoli C and Gallo A. Mucoepidermoid carcinoma of the tongue base mimicking an ectopic thyroid. Case Rep Otolaryngol. 2013; 2013:925630. | Article | PubMed Abstract | PubMed Full Text

14. Spiro RH, Koss LG, Hajdu SI and Strong EW. Tumors of minor salivary origin. A clinicopathologic study of 492 cases. Cancer. 1973; 31:117-29. | Article | PubMed

15. Spiro RH, Thaler HT, Hicks WF, Kher UA, Huvos AH and Strong EW. The importance of clinical staging of minor salivary gland carcinoma. Am J Surg. 1991; 162:330-6. | Article | PubMed

\section{Citation:}

Lawlor CM, Nelson RE, Doucet ME and Friedlander PL. A rare case of mucoepidermoid carcinoma of the lingual tonsil with cervical lymph node metastases. $J$ Cancer Ther Res. 2015; 4:1. http://dx.doi.org/10.7243/2049-7962-4-1 